\title{
The Frequency of Fibromyalgia in Patients With Tension-Type Headache
}

\author{
Yahya Qasim M. Taher ${ }^{1}$, Ali Abdulrahman Younis ${ }^{2, *}$,Ali Neamat Sulaiman Alallaf ${ }^{3}$ \\ 1 Neurology Unit, Department of Medicine, College of Medicine, University of Mosul, Mosul, Iraq \\ ${ }^{2}$ Rheumatology Unit, Department of Medicine, College of Medicine, University of Mosul, Mosul, Iraq \\ ${ }^{3}$ Neurology Unit, Department of Medicine, Ibn Sina Teaching Hospital, Mosul, Iraq \\ *Corresponding author Email: ali.younis7622@yahoo.com
}

\begin{abstract}
Fibromyalgia (FM) is a prevailing debilitating disorder that has been documented in patients with tension-type headache (TTH). The goal of this study was to determine the prevalence of fibromyalgia in TTH patients as well as the features of TTH patients with concomitant FM. One hundred patients with TTH and 100 apparently healthy subjects were conjoined in this study. The socio-demographic and headache characteristics of the patients were recorded. Patients with TTH had a considerably higher frequency of FM (34\%) when compared to the controls (9\%) TTH patients with FM had a substantially older mean age and a higher percentage of female participants than TTH patients without FM. Patients with comorbid fibromyalgia had greater headache frequency $(\mathrm{P}=0.02)$, headache intensity $(\mathrm{P}=0.003)$, and higher scores on the HIT-6 ( $\mathrm{P}=0.004)$, GAD -7 ( $=0.04)$, and PHQ-9 ( $\mathrm{p}=0.02)$, whereas there was no variation between the diseased patients and controls with regards to disease duration. In conclusion, there is a high frequency of FM in patients with TTH. Patients with coexistent FM and TTH tend to have more anxiety and depressive features, more severe headache, greater headache frequency, and when compared to people who do not have fibromyalgia, they are more likely to have a significant headache-related impairment.
\end{abstract}

Keywords: Fibromyalgia, Tension-type headache, Headache.

\section{INTRODUCTION}

Fibromyalgia (FM) is a prevalent disorder marked by chronic widespread pain, which is frequently accompanied by tenderness, fatigue, mood changes, sleep disturbances, and other somatic problems. [1, 2]. The most common kind of headache in the general population is tension-type headache (TTH). [3], as well as the world's second-most-common disorder. [4]. Comorbid fibromyalgia has been reported in patients with TTH in several studies [5-8]. Fibromyalgia is a devastating illness that, when combined with TTH, can increase morbidity [9].

The purpose of this study was to determine the frequency of FM in TTH patients as well as the features of TTH patients with comorbid FM.

\section{PATIENTS AND METHODS}

A total of 100 patients were included in this case-control research with TTH in the Neurology Unit, Department of Medicine in "Ibn Sina Teaching Hospital" in Mosul City, between March and November 2020. These patients were compared with 100 healthy individuals matched for age and sex who were considered the control group. They had no TTH or any type of headache. The study was conducted in conformity with the Declaration of Helsinki's principles, and all participants supplied written informed consent before to the study's start. TTH was diagnosed using the International Classification of Headache Disorders, 3rd Edition (ICHD-3) system. [10]. Patients with other types of headaches, neurological illnesses, or other recognized 
causes of widespread pain, such as endocrine, rheumatic, or systemic problems, were excluded from the study. Age, gender, BMI, marital status, employment position, and education status were all recorded, as well as headache characteristics (frequency, headache intensity, and duration of TTH). The diagnosis of FM was done according to the 2011 modification of the preliminary diagnostic criteria for FM released by the American College of Rheumatology in 2010 [11]. In addition, all the patients were assessed for the impact of headache, the presence of anxiety, and depression using the following scales:

The "Headache Impact Test-6 (HIT-6)" is a validated questionnaire used to measure the disturbance in the daily life of the patient caused by headache (range: 3678). This questionnaire includes six domains that assess how often recent headaches resulted in severe pain, how often they limit the ability to perform regular daily activities, and how often they led to the need to lay down, headache-related tiredness, irritability, or difficulty concentrating [12].

The "Patient Health Questionnaire-9 (PHQ-9)" is a validated depression screening tool. It consists of 9 statements of depression symptoms that are assessed on a scale of 0 to 3 (none at all/a few days/more than half of the days/nearly every day) over the past two weeks. [13].

The "Generalized Anxiety Disorder 7-item (GAD-7)" is a seven-item scale that assesses DSM-IV (Diagnostic and Statistical Manual of Mental Disorders, 4th edition) listed general anxiety symptoms. In this self-report measure, participants were asked to rate their anxietyrelated issues on a 4 -point scale $(0=$ hardly at all, to $3=$ almost every day) throughout the two weeks prior to the questionnaire administration. GAD-7 scores range from 0 to 21 , with higher GAD-7 scores indicating more severe anxiety [14].

Headache intensity was evaluated on a numerical rating scale of 0 to 10 , with 0 indicating "no pain" and 10 representing "the worst pain imaginable".

SPSS "Statistical Package for the Social Sciences" version 23 was used for statistical analysis. The mean and standard deviation of continuous variables were calculated. For the comparison of qualitative data, the Chi-square test was utilized. The differences between two means were calculated using the "student's t-test". Statistical significance was defined as a p-value of less than 0.05 .

\section{RESULTS}

One hundred patients with TTH, 38 males $(38 \%)$ and 62 females $(62 \%)$, their mean age $(38.53 \pm 12.23)$ years, and 100 healthy control group, 41 males $(41 \%)$ and 59 females $(59 \%)$, their mean age was $(36.4 \pm 8.45)$ years were included in this study. Both groups were age and gender-matched, with no significant statistical difference between them ( $\mathrm{p}$-value >0.05).

The frequency of FM in 100 patients with TTH was $(34 \%)$ compared to $(9 \%)$ in 100 healthy individuals $(\mathrm{P}=$ 0.00002 ) indicating a statistically significant difference between both groups as shown in Table 1 .

Table 1. Comparison of FM between patients with TTH and control group

\begin{tabular}{|l|l|l|l|}
\hline & $\begin{array}{l}\text { Cases(TTH) } \\
n=100\end{array}$ & $\begin{array}{l}\text { Controls } \\
n=100\end{array}$ & P-value \\
\cline { 1 - 2 } FM, n (\%) & $34(34)$ & $9(9)$ & 0.00002 \\
\cline { 1 - 2 } & $66(66)$ & $91(91)$ & \\
\hline
\end{tabular}

The socio-demographic features of TTH patients with and without FM are shown in Table 2. In TTH patients with FM, the average age and ration of female patients were significantly greater than in TTH patients without fibromyalgia. (48.94 \pm 9.87 vs. $\quad 33.17 \pm 9.61, \mathrm{p}<$ $0.0001 ; 79.4 \%$ vs. $53 \%, \mathrm{p}=0.01)$. Other sociodemographic characteristics such as BMI, occupational status, educational attainment, and marriage status were not significantly different between the groups. ( $p>0.05$ for all)

The characteristics of headache among TTH patients with and without FM are shown in Table 3. Patients with comorbid fibromyalgia had greater headache frequency $(\mathrm{P}=0.02)$, headache intensity $(\mathrm{P}=0.003)$, and higher scores on the HIT-6 $(\mathrm{P}=0.004), \mathrm{GAD}-7$ (P $=0.04)$, and PHQ-9 $(\mathrm{p}=0.02)$, whereas there was no difference between the cases and controls with regards to disease duration. 
Table 2. Socio-demographic featuresof TTH patients with and without FM

\begin{tabular}{|l|l|l|l|}
\hline Variable & $\begin{array}{l}\text { TTH } \\
\text { with FM, } \\
\mathrm{n}=34\end{array}$ & $\begin{array}{l}\text { TTH } \\
\text { withou } \\
\text { t FM, } \\
\mathrm{n}=66\end{array}$ & \\
\hline $\begin{array}{l}\text { Average } \\
\text { age (years) }\end{array}$ & $\begin{array}{c}48.94 \pm \\
9.87\end{array}$ & $\begin{array}{c}33.17 \pm \\
9.61\end{array}$ & $<0.0001$ \\
\hline $\begin{array}{l}\text { Gender } \\
\text { (F/M), (\%) }\end{array}$ & $79.4 / 20$. & $53 / 4$ & 0.01 \\
\hline $\begin{array}{l}\text { BMl } \\
\text { (F) }\end{array}$ & $26.3 \pm 6.5$ & $24.7 \pm 3$ & 0.11 \\
\hline $\begin{array}{l}\text { Education, } \\
\text { years }\end{array}$ & $\begin{array}{c}10.4 \pm 6.3 \\
\text { (\%) }\end{array}$ & $\begin{array}{c}11.5 \pm 5.4 \\
\text { (1) }\end{array}$ & 0.36 \\
\hline Employed, & $25(73.5)$ & $47(71.2$ & 0.63 \\
\hline
\end{tabular}

Table 3. Headache characteristics among TTH patients with and without FM

\begin{tabular}{|l|c|l|c|}
\hline Variable & $\begin{array}{c}\text { TTH with } \\
\mathrm{FM}, \mathrm{n}=34\end{array}$ & $\begin{array}{l}\text { TTH } \\
\text { without } \\
\mathrm{FM}, \mathrm{n}=66\end{array}$ & P value \\
\hline $\begin{array}{l}\text { Duration of } \\
\text { TTH,years }\end{array}$ & $6.2 \pm 5.4$ & $5.9 \pm 4.3$ & 0.76 \\
\hline $\begin{array}{l}\text { TTH } \\
\text { frequency } \\
\text { (number } \\
\text { per month) }\end{array}$ & $15.7 \pm 7.6$ & $12.6 \pm 5.5$ & 0.02 \\
\hline Headache & $5.5 \pm 2.3$ & $4.2 \pm 1.8$ & 0.003 \\
\hline
\end{tabular}

\begin{tabular}{|l|c|c|c|}
\hline intensity & & & \\
\hline HIT -6 & $61.7 \pm 6.4$ & $57.4 \pm 7.2$ & 0.004 \\
\hline GAD-7 & $6.3 \pm 5.4$ & $4.4 \pm 3.6$ & 0.04 \\
\hline PHQ-9 & $16.4 \pm 5.6$ & $12.9 \pm 7.5$ & 0.02 \\
\hline
\end{tabular}

\section{DISCUSSION}

In the current study, the frequency of FM among patients with TTH was $34 \%$, compared to $9 \%$ of healthy individuals which indicates a significant association between the two conditions (P-value = 0.00002). This finding was in accordance with previous studies which showed a high frequency of FM in TTH patients, ranging between $25.7 \%$ and 59\% [5-7]. The apparent difference in FM prevalence across studies could be due to the utilization of different FM classification criteria, or the inconsistency in the application of these criteria. The ACR has established clinical criteria that do not include examining tender spots is, but it does give a metric for assessing the intensity of symptoms that are common in FM. These new criteria would be easier to use and would make diagnosing FM comorbidity much easier.

The very high frequency of FM among TTH patients is not necessarily a representation of the TTH general population since the research was performed in a hospital-based neurology unit. There is a need for community-based studies to establish the association of these conditions in the general population.

This frequent association of TTH with fibromyalgia could be possibly attributed to a common pathophysiologic basis. As a common mechanism for both FM and TTH, central sensitization of pain neurons has been proposed [9]. The pathogenesis of TTH seems to involve peripheral and central factors [15]. Initially, pericranial myofascial structures start to hurt for a variety of causes, such as postural or dental problems [9, 16, 17]. It has been shown that TTH patients had an increased number of active and latent trigger sites, a forward head position, and reduced neck mobility [18, 19]. As a result, central sensitization occurs. Assessment of pain tolerance thresholds and suprathreshold stimulation were performed on these individuals revealed widespread hyperalgesia and a decrease in diffuse noxious inhibitory control function [20, 21]. 
TTH and FM may be induced by a similar imbalance in excitatory and inhibitory modulatory pain transmission regulation [9]. The spread of central sensitization beyond the cranium throughout the body may be an epiphenomenon of headache sensitization processing [9].

In the current study, patients with TTH and comorbid FM had the tendency to be older, and most were female. Our findings were in agreement with previous studies [6,7]. It is known that the frequency of FM increases with age and that both TTH and FM predominate in females. However, Gender variations in these diseases are not entirely understood, but they are most likely the consequence of a complex interplay between gonadal hormones, brain processes, and pain processing $[22,23]$.

In our study, the frequency of TTH was significantly greater in patients with FM than in those without FM. In a study done by "de Tommaso et al.," the frequency of headache was reported as one of the major discrimination variables for FM comorbidity [6, 9]. Increased headache frequency increases pain intensity in somatic areas beyond the cranium, and patients may be predisposed to FM [9]. In our study, Patients with comorbid fibromyalgia had significantly greater headache intensity and higher scores on the HIT-6. Our finding was in agreement with a previous report of increased headache severity and headache-related disability in patients with coexistant FM and TTH in comparison to those with TTH only [6].

Scores on PHQ-9 and GAD-7 were significantly greater in the patients with concomitant FM. Our finding was in agreement with a previous study by de Tommaso et al, which show increased depression and anxiety in patients with coexisting FM and TTH as compared to those with TTH only [6]. Whether depression and anxiety are induced by FM or TTH, or they are independent exacerbating factors for either or both of them is not clear. It has been shown that interconnections between anxiety,depression, and TTH may be linked to serotonin levels. [24]. A lower level of serotonin may be involved in the dysregulation of "descending antinociceptive systems", contributing to fibromyalgia and TTH [24, 25]. Mongini et al. reported that anxiety increases the degree of muscular tenderness in the head and neck, potentially promoting the progression into chronic headaches. As such, anxiety may initiate widespread myofascial pain and FM development in headache patients with increased cranial muscle soreness [26].
The primary drawback in the current study was the small number of participants. According to the findings of our study, it would be reasonable to suggest screening for coexisting fibromyalgia in the evaluation and management of TTH patients.

\section{CONCLUSIONS}

Patients with TTH have a high frequency of FM. TTH patients with concomitant FM had the tendency to be older, and most were females. In comparison to patients without fibromyalgia, individuals with fibromyalgia and TTH experienced more depressed symptoms, had more intense and frequent headaches, and were more likely to have severe headache-related impairment.

\section{AUTHORS' CONTRIBUTIONS}

The authors contributed equally to this study.

\section{REFERENCES}

[1] Goldenberg DL. Fibromyalgia syndrome. An emerging but controversial condition. JAMA. 1987; 257(20):pp. 2782-2787.

[2] Clauw DJ. Fibromyalgia: A clinical review. JAMA 2014; 311(15): $\quad$ pp.1547-1555 doi:10.1001/jama.2014.3266.

[3] Jensen RH. Tension-Type Headache - The Normal and Most Prevalent Headache. Headache. 2018; 58(2):pp. 339-345. doi:10.1111/head.13067.

[4] Martelletti P, Birbeck GL, Katsarava Z, Jensen RH, Stovner LJ\& Steiner TJ. The Global Burden of Disease survey 2010, lifting the burden and thinking outside-the-box on headache disorders. J Headache Pain 2013; 14:pp. 13. doi:10.1186/1129-2377-14-13

[5] de Tommaso M, Sardaro M, Serpino C, Costantini F, Vecchio E, Prudenzano MP, et al . Fibromyalgia comorbidity in primary headaches. Cephalalgia. 2009 Apr; 29(4):pp. 453-64. doi:10.1111/j.14682982.2008.01754.

[6] de Tommaso M, Federici A, Serpino C, Vecchio E, Franco G, Sardaro M, et al. Clinical features of headache patients with fibromyalgia comorbidity. J Headache Pain. 2011 Dec; 12(6):pp. 629-38. doi:10.1007/s10194-011-0377-6.

[7] Cho SJ, Sohn JH, Bae JS, Chu MK. Fibromyalgia among patients with chronic migraine and chronic tension-type headache: A multicenter prospective cross-sectional study. Headache. 2017; 
57(10):1583-1592. doi: 10.1111/head.13191. Epub 2017 Sep 22.

[8] Schur EA, Afari N, Furberg H, Olarte M, Goldberg $\mathrm{J}$, Sullivan PF, et al. Feeling bad in more ways than one: comorbidity patterns of medically unexplained and psychiatric conditions. J Gen Intern Med. 2007 Jun; 22(6):818-21. doi: 10.1007/s11606-007-01405. PMID: 17503107; PMCID: PMC2219854.

[9] de TommasoM. Prevalence, clinical features and potential therapies for fibromyalgia in primary headaches. Expert Rev Neurother. 2012; 12(3):287-295. doi: 10.1586/ern.11.190. PMID: 22364327.

[10] Headache Classification Committee of the International Headache Society (IHS) The International Classification of Headache Disorders, 3rd edition. Cephalalgia 2018; 38:1. doi:10.1177/0333102417738202.

[11] Wolfe F, Clauw DJ, Fitzcharles MA, Goldenberg DL, Häuser W, Katz RS, et al. Fibromyalgia criteria and severity scales for clinical and epidemiological studies: a modification of the ACR Preliminary Diagnostic Criteria for Fibromyalgia. J Rheumatol 2011; 38:pp. 1113. doi: 10.3899/jrheum.100594. Epub 2011 Feb 1. PMID: 21285161 .

[12] Kosinski M, Bayliss MS, Bjorner JB, Ware JE , Garber WH, Batenhorst A, et al. A six-item shortform survey for measuring headache impact: the HIT-6. Qual Life Res. 2003; 12:pp. 963-974. doi: 10.1023/a:1026119331193. PMID: 14651415.

[13] Kroenke K, Spitzer RL, Williams JB. The PHQ-9: validity of a brief depression severity measure. J Gen Intern Med. 2001; 16:pp. 606-613. doi:10.1046/j.1525-1497.2001.016009606.x

[14] Spitzer RL, Kroenke K, Williams JBW, Löwe B. A Brief Measure for Assessing Generalized Anxiety Disorder: The GAD-7. Arch Intern Med. 2006; 166(10):1092-1097.

doi:10.1001/archinte.166.10.1092

[15] Jensen R. Peripheral and central mechanisms in tension-type headache: an update. Cephalalgia 2003; 23 Suppl 1:pp. 49. doi:10.1046/j.14682982.2003.00574.x

[16] Bendtsen L, Fumal A, Schoenen J. Tension-type headache: mechanisms. Handb Clin Neurol 2010; 97:pp. 359.

[17] Bendtsen L, Fernández-de-la-Peñas C. The role of muscles in tension-type headache. Curr Pain Headache Rep 2011; 15:pp. 451. doi:10.1016/S0072-9752(10)97029-2
[18] Fernández-de-Las-Peñas C, Cuadrado ML, Pareja JA. Myofascial trigger points, neck mobility, and forward head posture in episodic tension-type headache. Headache 2007; 47:pp. 662. doi:10.1111/j.1526-4610.2006.00632.x

[19] Fernández-de-Las-Peñas C, Alonso-Blanco C, Cuadrado ML, Gerwin RD, Pareja JA. Myofascial trigger points and their relationship to headache clinical parameters in chronic tension-type headache. Headache. 2006 Sep; 46(8):pp. 1264-72. doi:10.1111/j.1526-4610.2006.00440.x

[20] Sandrini G, Rossi P, Milanov I, Serrao M, Cecchini A, Nappi G. Abnormal Modulatory Influence of Diffuse Noxious Inhibitory Controls in Migraine and Chronic Tension-Type Headache Patients. Cephalalgia. 2006; 26(7):pp. 782-789. doi:10.1111/j.1468-2982.2006.01130.x

[21] Pielsticker A, Haag G, Zaudig M, Lautenbacher S. Impairment of pain inhibition in chronic tensiontype headache. Pain. 2005; 118(1-2):pp. 215. doi: 10.1016/j.pain.2005.08.019.

[22] Aloisi AM, Bonifazi M. Sex hormones, central nervous system and pain. Horm Behav. 2006 Jun; 50(1):pp. 1-7. doi:10.1016/j.yhbeh.2005.12.002.

[23] Yunus MB. Gender differences in fibromyalgia and other related syndromes. J Gend Specif Med. 2002 Mar-Apr; 5(2):pp. 42-47.

[24] Matta A, Moreira P. Depressive symptoms and anxiety in patients with chronic and episodic tension-type headache. Arq Neuropsiquiatr. 2003; 61 (4):pp. 991-994. doi:10.1590/s0004282x2003000600019

[25] Becker S, Schweinhardt P. Dysfunctional neurotransmitter systems in fibromyalgia, their role in central stress circuitry and pharmacological actions on these systems. Pain Res Treat 2012; 2012:pp. 1-10. doi:10.1155/2012/741746.

[26] Mongini F, Ciccone G, Deregibus A, Ferrero L, Mongini T. Muscle tenderness in different headache types and its relation to anxiety and depression. Pain. 2004 Nov; 112(1-2):pp. 59-64. doi: 10.1016/j.pain.2004.07.025. 